\title{
Muscle soreness, swelling, stiffness and strength loss after intense eccentric exercise
}

\author{
Maggie J. Cleak MSc and Roger G. Eston DPE* \\ Wolverhampton School of Physiotherapy, New Cross Hospital, Wolverhampton, UK; and *University of \\ Liverpool, Department of Movement Science and Physical Education, Liverpool, UK
}

\begin{abstract}
High-intensity eccentric contractions induce performance decrements and delayed onset muscle soreness. The purpose of this investigation was to study the magnitude and time course of such decrements and their interrelationships in 26 young women of mean(s.d.) age 21.4(3.3) years. Subjects performed 70 maximal eccentric contractions of the elbow flexors on a pulley system, specially designed for the study. The non-exercised arm acted as the control. Measures of soreness, tenderness, swelling (SW), relaxed elbow joint angle (RANG) and isometric strength (STR) were taken before exercise, immediately after exercise (AE), analysis of variance and at 24-h intervals for 11 days. There were significant $(P<0.01$, analysis of variance) changes in all factors. Peak effects were observed between 24 and $96 \mathrm{~h}$ AE. With the exception of STR, which remained lower $(P<0.01)$, all variables returned to baseline levels by day 11. A non-significant correlation between pain and STR indicated that pain was not a major factor in strength loss. Also, although no pain was evident, RANG was decreased immediately AE. There was no relationship between SW, RANG and pain. The prolonged nature of these symptoms indicates that repair to damaged soft tissue is a slow process. Strength loss is considered particularly important as it continues when protective pain and tenderness have disappeared. This has implications for the therapeutic management of patients with myopathologies and those receiving eccentric exercise for rehabilitation.
\end{abstract}

Keywords: Muscle soreness, eccentric exercise

Delayed onset muscle soreness (DOMS) results from high-intensity work involving eccentric muscular contractions ${ }^{1-4}$. This is attributed to the high force characteristics of eccentric contraction ${ }^{5,6}$, which induces muscle damage ${ }^{7-9}$. It is also associated with muscle shortening, swelling and loss of strength.

The majority of research on DOMS has focused on underlying pathophysiological processes. Although its exact causes are not known for certain, theories involving myofibrillar disruption and connective tissue damage are currently proposed ${ }^{10-14}$. The

Address for correspondence: Dr Roger G. Eston, Department of Movement Science and Physical Education, University of Liverpool, PO Box 147, Liverpool, L69 3BX, UK

(C) 1992 Butterworth-Heinemann Ltd 0306-3674/92/040267-06 physical correlates of DOMS and their temporal relationships have received less attention. Few studies have monitored the temporal nature of the strength loss for longer than one week ${ }^{15,16}$ and there have been conflicting findings concerning the duration of the strength loss ${ }^{1,15,17-19}$. Similarly, few studies have monitored changes in joint range of motion and its association with DOMS ${ }^{9,20-22}$ and only one has investigated the phenomenon for as long as 6 days after exercise ${ }^{23}$.

A problematic aspect of DOMS is the measurement of pain. Evaluation is necessarily subjective and a variety of pain scales have evolved to quantify this variable. These include verbal rating scales ${ }^{11,24}$, numerical rating scales 22,25 and a visual analogue scale $^{26}$. The reliability of the latter scale has been reported previously ${ }^{27}$. A method has also been proposed to quantify muscle 'tenderness' with a pressure transducer ${ }^{1}$, which has been used to locate the distribution and severity of tenderness in a number of studies ${ }^{15}, 18,22,28$.

The purpose of this study was to provide a description of changes over an 11-day period of perceived soreness, muscle tenderness, upper arm swelling, muscle shortening and isometric strength loss, as a result of damaging eccentric exercise, in a group of young women.

\section{Methods}

A total of 26 female physiotherapy students (mean(s.d.) age 21.4(3.3) years, mean(s.d.) height $160.0(5.0) \mathrm{cm}$, mean(s.d.) weight $59.8(7.9) \mathrm{kg}$ ) volunteered to perform an eccentric exercise regimen designed to produce DOMS in the elbow flexor goup (primarily biceps brachii and brachialis). The nonexercised arm was used as a control. Measures of perceived muscle soreness, tenderness, isometric strength, arm circumference and range of relaxed elbow extension were taken on the 'treatment' and 'control' arm immediately before and immediately after exercise, and at $24-h$ intervals for the next 11 days.

To ensure repeatability of goniometric, myometric and circumference measures, both arms of each subject were marked at the proximal and distal musculotendinous (MT) junctions and at the midbelly of the biceps. 


\section{Measurement of soreness}

This was measured by a visual analogue soreness (VAS) scale ${ }^{26}$, which has 10 numerically rated, verbal descriptions of pain. The subject moved the sliding indicator according to the level of soreness when the elbow was actively extended.

\section{Measurement of tenderness}

This was based on the method described by Newham et al. ${ }^{1}$ using the Penny and Giles myometer (Christchurch, UK). The subject indicated when the sensation of pressure changed to discomfort and the force at that point was recorded.

\section{Isometric strength of elbow flexors}

The subject sat in a standardized position in the apparatus which was also used for the eccentric exercise. This was modified from an original construction described by Jones and Newham ${ }^{29}$. A simplified line diagram of the apparatus is shown in Figure 1. The winch (Dutton Laison Winch No. 02810, Raymond Bills, Stourbridge, UK; mechanical advantage 17:1) and seating were arranged so that both arms could be tested under identical conditions. The recorded signal was visible to the subject to provide feedback, and verbal encouragement was given. Output from the strain gauge was recorded on a chart recorder (Byron Pen Recorder, Model 28000, Bryans Southern Instruments). Paper speed was set at $0.5 \mathrm{~mm} \mathrm{~s}^{-1}$ and sensitivity was set at $100 \mathrm{mV}$. The subject produced a maximum isometric voluntary contraction of the elbow flexors for $5 \mathrm{~s}$. This was repeated three times, with $30 \mathrm{~s}$ rest intervals. The mean value was recorded.

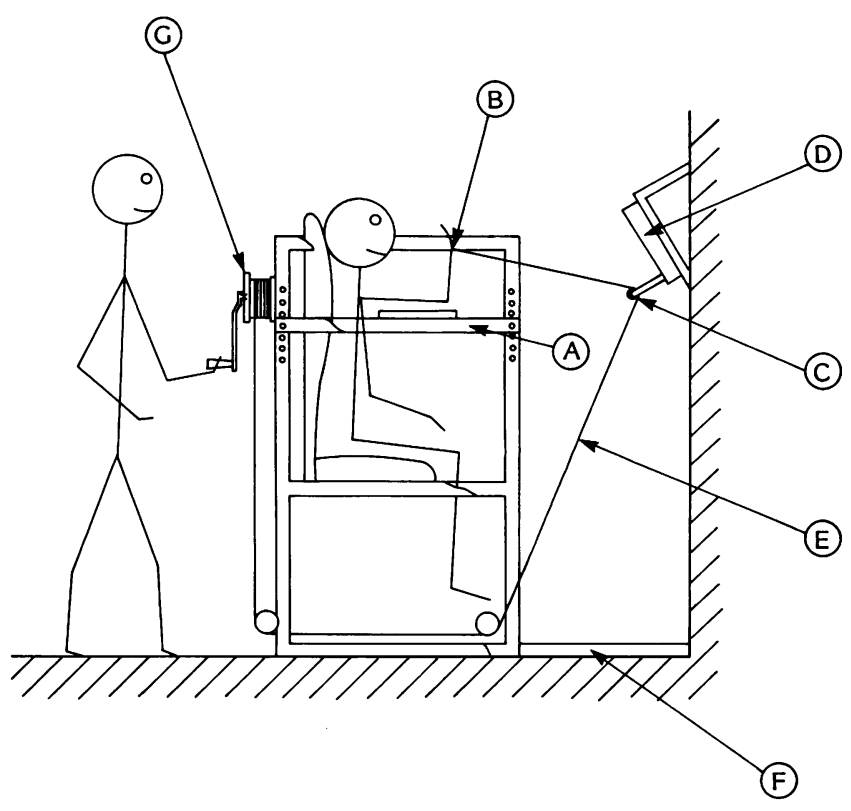

Figure 1. Simplified line diagram of the apparatus used to induce soreness of the elbow flexors by intense eccentric exercise. A. Adjustable height shelf; B. Padded cuff; C. Pulley; D. Strain gauge mounted on cantilever; E. Wire cable connected to winch; F. Metal frame to prevent forward movement of chair; G. Winch

\section{Upper arm circumference}

Upper arm circumferences were measured with the subject in the zero anatomical position and the arm muscles relaxed. Two measurements were made at each level and the average value was recorded.

\section{Elbow angle}

Muscle contractures of the forearm flexor muscles were assessed by measuring the relaxed elbow angle. This is an indirect measure of muscle stiffness/soft tissue shortening which has been used in previous studies $^{22,30}$. The elbow joint angle was determined by a Universal goniometer (Zimmer Orthopaedic, Bridgend, UK) with the subject standing and resting the arm naturally at the side. The goniometer was aligned for the elbow joint using the skin markings as described previously. To minimize parallax error, the investigator was seated so that her vision was level with the subject's elbow joint. The average of two readings was taken. The reliability and validity of this technique has been reported previously, with coefficients being $\geqslant 0.90^{30-32}$.

\section{Eccentric exercise protocol to produce DOMS}

The arm was positioned at full flexion for the commencement of each eccentric contraction. After two practice trials, the subject was instructed to hold the elbow in the flexed starting position and verbally encouraged to work maximally. At the command ' $1,2,3 \ldots$ hold it there' the investigator forcibly extended the forearm with the winch. The damaging exercise consisted of 70 maximum voluntary eccentric contractions, each one lasting for $3 \mathrm{~s}$ with a $12-\mathrm{s}$ rest. During the rest period the investigator returned the subject's arm to the forearm-flexed starting position, so that the subject performed no concentric action against resistance. A 1-min recovery period was allowed after each set of 10 .

Data were analysed by a two-factor $(2 \times 11)$ ANOVA with repeated measures across time using the SPSS- $\mathrm{X}^{33}$ statistical software. Post hoc multiple comparisons were made using a Newman-Keuls test.

\section{Results \\ Temporal differences \\ Pain/soreness}

Perceived soreness increased significantly $(P<0.01)$ in the experimental arm $24 \mathrm{~h}$ after exercise. This peaked after 3 days and gradually subsided by day 8 , when pain was no longer perceived by the majority of subjects (Figure 2).

\section{Tenderness}

There was no change in tenderness at the proximal MT junction. However, tenderness at the mid-belly biceps and distal MT junction increased significantly $(P<0.01)$ immediately after exercise and peaked after 2 days. It then subsided until tenderness reached pre-exercise values by day 7 (Figure 2). 


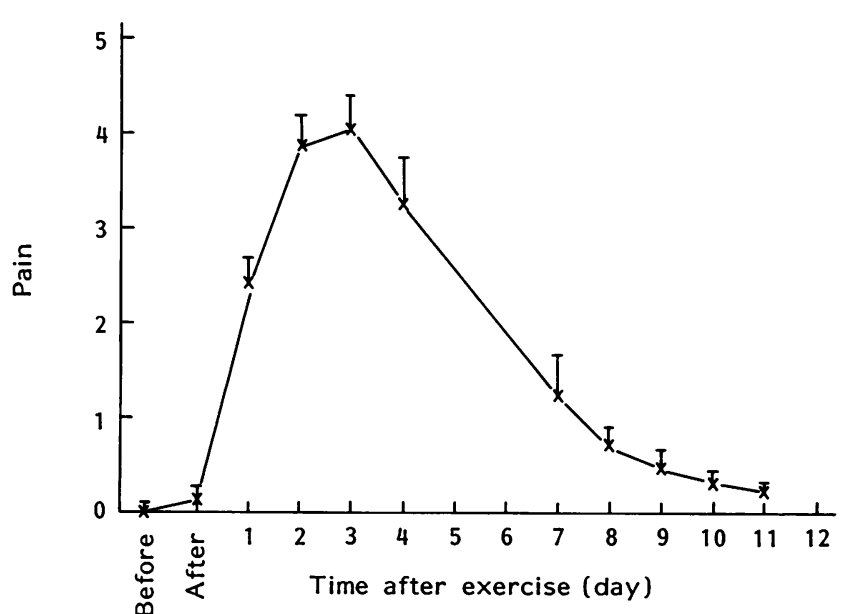

Figure 2. Change in perceived pain on active stretch (VAS Scale 0-10) and tenderness (myometer) of elbow flexors after intense eccentric exercise. Values are mean(s.e.m.)

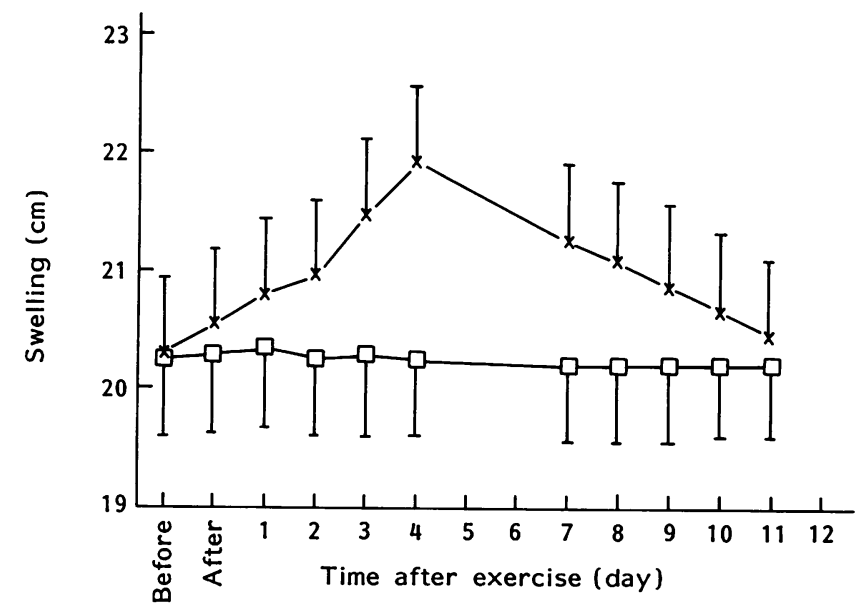

Figure 3. Change in circumference at distal musculotendinous (MT) region of elbow flexors after intense eccentric exercise. Control arm, $\square$; experimental arm, $x$. Values are mean(s.e.m.)

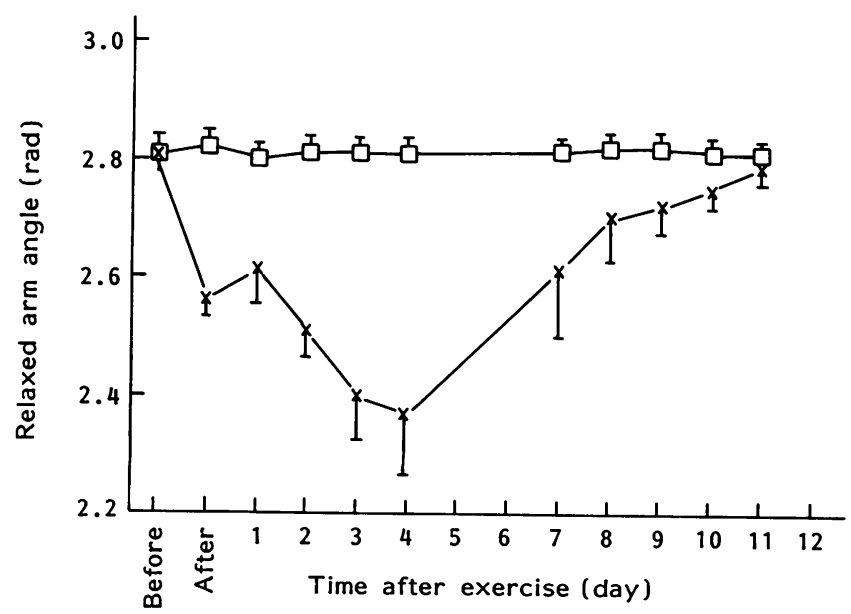

Figure 4. Change in resting angle of elbow after intense eccentric exercise. Control arm, $\square$; experimental arm, $x$. Values are mean(s.e.m.)
Swelling

Circumferences at the distal MT junction and mid-belly biceps were significantly higher $(P<0.01)$ by day 3 . They were highest by day 4 and gradually subsided by day 10 . At peak levels, the mean difference was $1.0 \mathrm{~cm}$ and $1.8 \mathrm{~cm}$ for the mid-belly and distal MT junction, respectively (Figure 3).

\section{Resting angle}

Resting angle decreased significantly $(P<0.01)$ immediately after exercise. It was lowest on day 4 when the mean decrease was approximately $26^{\circ}$ $(0.45 \mathrm{rad})$. By day 10 this had returned to the pre-exercise level (Figure 4).

\section{Strength}

A reduction in strength $(P<0.01)$ occurred immediately after exercise. Maximum strength loss $(90.6 \mathrm{~N}$; $46 \%$ of pre-exercise values) occurred $24 \mathrm{~h}$ later. Isometric strength remained $20 \%$ lower $(P<0.01)$ by day 11 (Figure 5).

\section{Temporal relationships}

\section{Tenderness and soreness}

There were significant correlations $(P<0.05)$ between tenderness and soreness $(r=-0.41)$ at the mid-belly biceps and distal MT junction $(r=-0.54)$. By day 3, when soreness was highest, these correlations increased to -0.77 and -0.59 , respectively.

\section{Strength and soreness}

There was no relationship between strength loss and soreness on day 1 , when strength loss was greatest. However, a significant $(P<0.01)$ relationship $(r=$ -0.60 ) occurred when soreness was highest on day 3.

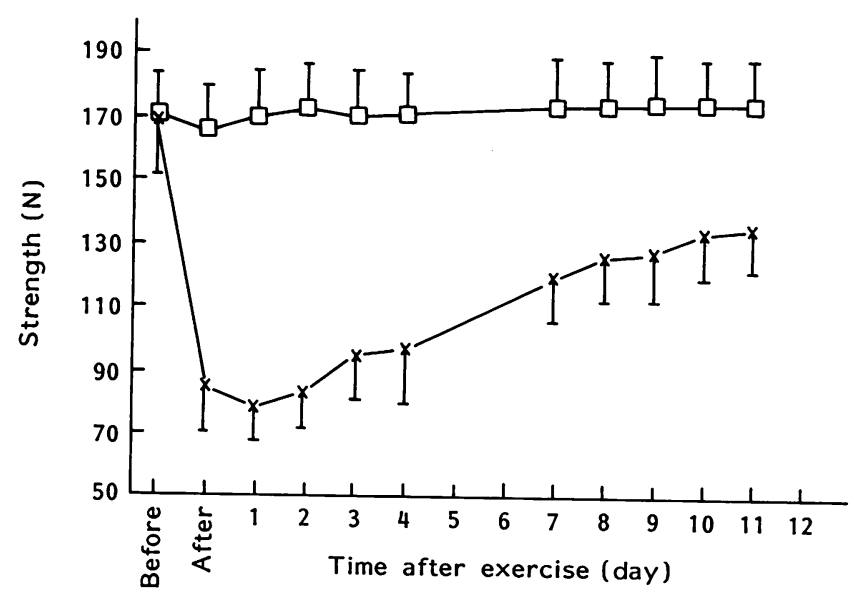

Figure 5. Change in isometric strength of elbow flexors after intense eccentric exercise. Control arm, $\square$; experimental arm, $x$. Values are mean(s.e.m.) 


\section{Resting angle, soreness and swelling}

Despite a decrease in resting angle immediately after exercise, there was no increase in the perception of soreness at this time. However, significant $(P<0.01)$ correlations between resting angle and soreness were observed on day 3 when soreness was highest $(r=$ $-0.76)$ and on day 4 when resting angle was lowest $(r$ $=-0.74)$. No significant association was observed between swelling and soreness or swelling and resting angle at any time.

\section{Discussion}

The protocol used in this study was effective in producing significant soreness, tenderness, swelling, muscle/soft tissue shortening and strength loss. The protocol was based on a similar investigation ${ }^{22}$, although the sample size in the present study was considerably larger (compare references 7 and 26).

\section{Tenderness and pain}

The majority of subjects reported most tenderness around the distal MT junction, which is consistent with previous observations ${ }^{1,10,34}$. From their research, Newham et al. ${ }^{1}$ and Edwards et al. ${ }^{34}$ concluded that delayed soreness observed in their studies was most likely due to mechanical damage, predominantly in the connective tissue in the distal MT region. The present study supports the suggestion that localized soreness may be due to mechanical damage to the connective tissue as well as to the muscle itself ${ }^{1,11,35}$.

Greater pain was perceived during active extension of the arm than when resting. The extension pain was accompanied by a visible reduction in resting angle (although the exact change was not measured in this study). Free nerve endings that are mechanically stimulated are mainly found at the MT junction and in connective tissue ${ }^{37}$. Lengthening of the muscle fibres imposes additional tension and stretch on the connective tissue and appears to increase the localized soreness in this region. It may suggest that there is a link between extension pain and the degree of muscle shortening.

\section{Swelling and resting angle}

The delayed onset of swelling (2-4 days) has been documented previously $9,21,37$, although no study has documented the time course of swelling lasting as long as 9 days. As with soreness and tenderness, considerable individual variation in swelling was observed. Although girths increased by $1-2 \mathrm{~cm}$ by day 4, a large minority of subjects experienced minimal or no swelling. This could explain why some studies, using small samples, have observed no significant increase in swelling.

A peak decrement in resting angle between $48 \mathrm{~h}$ and $72 \mathrm{~h}$ after exercise has been observed previously ${ }^{30,38,39}$. These studies did not measure swelling. Howell et al. ${ }^{21}$ observed that swelling and alteration in resting angle occurred at the same 48-h period, which led them to suggest that swelling in perimuscular connective tissue restricted range of motion. In the present study, the greatest change in resting angle (day 4) coincided with peak muscle soreness and swelling. Although one would expect that a reduction in resting angle would be associated with an increase in cross-sectional area, no significant association between swelling and resting angle was observed. This is consistent with previous findings ${ }^{9}$. In addition, there was no association between soreness and swelling at any time, which is contrary to the findings of others ${ }^{26,38,39}$. A limitation of the present study may be that circumferential assessments of swelling are less sensitive than the volumetric technique, such as that used by Bobbert et $a .^{26}$; the standard error reported by these investigators was in the region of $20 \mathrm{ml}^{26}$. The $4-5 \mathrm{~mm}$ standard error for the circumference measures observed in the present study would incur a substantially larger volumetric error when this is calculated mathematically. Thus, the association between changes in circumference, soreness and changes in resting angle may have been confounded by measurement error.

Yackzan et al..$^{20}$ observed a significant relationship between pain and loss of range soon after eccentric exercise. In the present study, despite a significant loss of movement range immediately after exercise, no soreness was experienced. Although pain might be expected to produce protective muscle spasm and therefore reduce the joint angle, electromyographic studies have provided no evidence for this phenomenon $^{21,22}$. Some investigators have speculated that the cause of muscle shortening may be due to an abnormal increase of calcium ions in the muscle cell $^{9,30,40-42}$, which has been attributed to a defect in the sarcoplasmic reticulum after damaging exercise $^{1,43-45}$. Although this hypothesis is an attractive one, Ebbeling and Clarkson ${ }^{42}$ have expressed caution in that the proposed phenomenon of increased intracellular calcium concentrations in exercisedamaged muscles requires verification and that the location of the defect has yet to be identified positively.

\section{Strength}

Few studies have monitored the time course of strength loss after eccentric exercise for longer than a few days. The results of this study are comparable with studies in which an immediate loss in isometric strength after exercise has been observed which lasts for a long period $9,15,30$. The suggestion that pain and soreness may have impeded the development of tension by inhibition of effort ${ }^{24}$ is not supported by the current data, as no pain was experienced immediately after exercise, despite a significant reduction $(P<0.01)$ in isometric strength. In addition, there was no association between pain and strength loss on day 1 when maximum strength loss (46\% of pre-exercise values) occurred. Previous studies using electrical stimulation to enhance maximal isometric tension have also demonstrated that pain does not cause force decrements ${ }^{1,15}$.

The mechanisms of delayed onset muscle soreness, which are associated with strength loss, have recently 
been reviewed by the authors ${ }^{46}$. The process of recovery and regeneration is a long one. Muscle biopsy studies have shown increased myofibrillar damage involving the Z-band, and sarcomere disruption, which becomes more widespread and more severe at 3 days after exercise ${ }^{13,14}$. Indeed, one study has observed myofibrillar necrosis with no evidence of regeneration 10 days after strenuous eccentric exercise $^{47}$. Whatever the mechanisms of damage, the prolonged delay of strength recovery observed in the present study and others, has implications particularly in events where a large component of eccentric activity is involved, e.g. marathon running, climbing, contact sports. Pain normally serves a protective function. If significant muscle weakness, of which the subject is unaware, is present, and soreness is no longer perceived, joints may be put under undue stress, as the affected muscles may not be able to provide their normal stabilizing function. The assumption here is that the isometric force decrement, observed in this study and others, indicates a commensurate decrement in concentric and eccentric muscle tension after damaging eccentric exercise. Several studies have confirmed this phenomenon ${ }^{13,16,19}$. Golden et al. ${ }^{16}$ observed that eccentric strength returned to baseline after 6 days, but concentric strength had still not returned to baseline 10 days after strenuous eccentric exercise.

These findings may also have clinical relevance. Rehabilitation exercise programmes are used routinely by physiotherapists to increase muscular strength in patients with myopathies, e.g. muscular dystrophy. Programmes involving a large eccentric component may need to be avoided in case further damage is caused. Second, routine rehabilitation exercise programmes involving the lowering of free weights are often prescribed for quadriceps strengthening after lower limb trauma. In the light of findings from this and other studies, the amount of eccentric work given may need more careful monitoring. If muscle damage and strength loss are a result of the programme, unwanted stresses in the knee joint may be consequent upon a temporary loss of protective muscle function. The exercise regimen may exacerbate problems in the very structures it is prescribed to protect and strengthen. Also, subjective experience of pain, swelling and stiffness, if produced by a rehabilitation programme, might discourage the patient from continuing with the exercise.

\section{References}

1 Newham DJ, Mills KR, Quigley BM, Edwards RHT. Pain and fatigue after concentric and eccentric muscle contractions. Clin Sci 1983; 64: 55-62.

2 Byrnes WC, Clarkson PM, Katch FI. Muscle soreness following resistance exercise with and without eccentric contractions. Res $Q$ Exerc Sport 1985; 56: 283-5.

3 Friden J, Sfakianos PN, Hargens AR. Muscle soreness and intramuscular fluid pressure: comparison between eccentric and concentric load. J Appl Physiol 1986; 61: 2175-9.

4 Knuttgen HG. Human performance in high intensity exercise with concentric and eccentric muscle contractions. Int J Sports Med 1986; 7: 6-9.

5 Rodgers KL, Berger RA. Motor unit involvement - tension during maximum voluntary concentric, eccentric and isometric contractions of the elbow flexors. Med Sci Sports 1974; 6: 253-9.
6 Newham DJ. The consequences of eccentric contractions and their relationship to delayed onset muscle pain. J Appl Physiol 1988; 57: 353-9.

7 Tiidus PM, Ianuzzo CD. Effects of intensity and duration of muscular exercise on delayed soreness and serum enzyme activities. Med Sci Sports Exerc 1983; 15: 461-5.

8 Buroker KJ, Schwane JA. Does post-exercise static stretching alleviate exercise-induced muscle soreness? Med Sci Sports Exerc 1987; 19(2) (Suppl): 216A.

9 Clarkson PM, Tremblay I. Exercise induced muscle damage, repair and adaptation in humans. J Appl Physiol 1988; 65: 1-6.

10 Komi PV, Buskirk ER. Effect of eccentric and concentric muscle conditioning on tension and electrical activity of human muscle. Ergonomics 1972; 15: 417-34.

11 Abraham WM. Factors in delayed onset muscle soreness. Med Sci Sports Exerc 1977; 9: 11-20.

12 Friden J, Sjöstrom M, Ekblom B. A morphological study of delayed muscle soreness. Experientia 1981; 37: 506-7.

13 Friden J, Sjöstrom M, Ekblom B. Myofibrillar damage following intense eccentric exercise in man. Int J Sports Med 1983; 4: 170-6.

14 Newham DJ, McPhail G, Mills KR, Edwards RHT. Ultrastructural changes after concentric and eccentric contractions at long and short length. J Neurol Sci 1983; 61: 109-22.

15 Newham DJ, Jones DA, Clarkson PM. Repeated high force eccentric exercise: effects on muscle pain and damage. J Appl Physiol 1987; 63: 1381-6.

16 Golden CL, Graves JE, Buchanan P, Dudley G. Eccentric and concentric strength after repeated bouts of intense exercise Med Sci Sports Exerc 1991; 23 (Suppl): 655A.

17 Davies CTM, White MJ. Muscle weakness following eccentric work in man. Pflugers Arch 1981; 392: 168-71.

18 Newham DJ, Jones DA, Edwards RHT. Large delayed plasma creatine kinase changes after stepping exercise. Muscle Nerve 1983; 6: 380-5.

19 Colliander EB, Tesch PA. Effects of acute concentric and eccentric exercise on rate of force recovery. Med Sci Sports Exerc 1987; 19 (Suppl): 214A.

20 Yackzan L, Adams C, Francis KT. The effects of ice massage on delayed muscle soreness. Am J Sports Med 1984; 12: 159-65.

21 Howell JN, Chila AG, Ford G, David D, Gates T. An electromyographic study of elbow motion during post exercise muscle soreness. J Appl Physiol 1985; 58: 1713-18.

22 Jones DA, Newham DJ, Clarkson PM. Skeletal muscle stiffness and pain following eccentric exercise of the elbow flexors. Pain 1987; 30: 233-42.

23 Donnelly AE, Clarkson PM, Maughan RJ. Effects of light exercise on exercise damaged muscle. Med Sci Sports Exerc 1988; 20 (Suppl): 446A.

24 Talag T. Residual muscle soreness as influenced by concentric, eccentric and static contractions. Res $Q$ 1973; 44: 458-69.

25 Byrnes WV, Clarkson PM. Delayed onset muscle soreness and training. Clin Sports Med 1986; 5: 605-14.

26 Bobbert MF, Hollander AP, Huijing PA. Factors in delayed onset muscle soreness of man. Med Sci Sports Exerc 1986; 18: 75-81.

27 Zusman $M$. The absolute visual analogue scale. Aust. J Physiother 1986; 32: 244-6.

28 Newham DJ, Jones DA, Ghosh G, Aurora P. Muscle fatigue and pain after eccentric contractions at long and short length. Clin Sci 1988; 74: 553-7.

29 Jones DA, Newham DJ. A simple apparatus for eccentric or concentric exercise of the biceps. J Physiol 1985; 365: 10P.

30 Nosaka K, Clarkson PM, McGuiggin ME, Byrne JM. Time course of muscle adaptation after high force eccentric exercise. Eur J Appl Physiol 1991; 63: 70-6.

31 Fish DR, Wingate L. Source of goniometric error at the elbow. Phys Ther 1985; 65: 1666-70.

32 Gajdosik RL, Bogannon RW. Clinical measurement of range of motion: review of goniometry emphasizing reliability and validity. Phys Ther 1987; 67: 1867-72.

33 Statistical Package for the Social Sciences, SPSS- $X$, Chicago, Illinois, USA.

34 Edwards RHT, Mills KR, Newham DJ. Measurement of severity and distribution of experimental muscle tenderness. J Physiol 1981; 317: 1-2P.

35 Asmussen E. Observations on experimental muscle soreness. Acta Rheum Scand 1956; 2: 109-16. 
36 Casey KL. Neural mechanisms of pain: an overview. Acta Anaesthiol Scand 1982; 74: 13-20.

37 Hill DW, Richardson JD. Effectiveness of $10 \%$ trolamine salicylate cream on muscular soreness induced by a reproducible program of weight training. J Orthop Sports Phys Ther 1989; 11: 19-23.

38 Newham DJ, Jones DA. Intramuscular pressure in the painful human biceps. Clin Sci 1985; 69 (Suppl): 12, 27P.

39 Friden J, Seger J, Ekblom B. Sublethal muscle fibre injuries after high tension anaerobic exercise. Eur J Appl Physiol 1988; 57: $360-8$.

1989; 21(2) (Suppl): 531A

40 Armstrong RB. Mechanisms of exercise-induced delayed onset muscle soreness: a brief review. Med Sci Sports Exerc 1984; 16: 529-38.

41 Newham DJ, Jones DA, Tolfree SE, Edwards RHT. Skeletal muscle $99 \mathrm{~m}$ technetium pyrophosphate uptake, enzyme release and muscle pain following stepping exercise. Eur J Appl Physiol 1985; 55: 106-22.

42 Ebbeling CB, Clarkson PM. Exercise induced muscle damage and adaptation. Sports Med 1989; 7: 207-34.

43 Brody IA. Muscle contracture induced by exercise. $N$ Engl J Med 1969; 281: 187-92.

44 Davies CTM, White MJ. Muscle weakness following eccentric work in man. Pflugers Arch 1981; 392: 168-71.

45 Newham DJ, Jones DA, Clarkson PM. Repeated high-force eccentric exercise: effects on muscle pain and damage. J Appl Physiol 1987; 63: 1381-6.

46 Cleak MJ, Eston RG. Delayed onset muscle soreness: mechanisms and management. J Sports Sci 1992; 10: 325-41.

47 O'Reilly KP, Warhol MJ, Fielding RA, Frontera WR, Meredith $\mathrm{CN}$, Evans WJ. Eccentric exercise induced muscle damage impairs muscle glycogen repletion. J Appl Physiol 1987; 63: 252-6. 